\section{Using Assessment to Inform Instruction for Early Literacy: A School's Story}

\section{Dorothy R. Spence}

$\mathrm{T}$ he difference between using assessment to make a statement about where exactly a students stands in relation to the expectations and to make decisions about what that child should be taught next is subtle but extremely important in the beginning stages of the acquisition of reading skills. Teachers have always, to a certain extent, tried to do this and this article explores our attempt at St. Helen Catholic Elementary School in Hamilton to use assessment to do strategic teaching.

St. Helen, a Kindergarten to Grade Eight school, meets the criteria, as articulated by the Ontario Ministry of Education, to be designated as a Learning Opportunities School. The characteristic of our socio-economic catchment area features low income, high unemployment, low education of parents, high immigration, high transience of students and many single parent led households. In the fall of 1997, when I became principal of the school, teachers indicated significant concerns with the children's acquisition of reading skills. The results from the first EQAO testing administered in May 1997 indicated that only twelve percent of the grade three students were reading at levels three and four as articulated by the Ontario Ministry of Education. The teachers felt that the reading difficulties demonstrated by the grade three students were consistent with what they saw in their classrooms. Further, teachers truly believed, and this is borne out by research, that if a student was not reading at grade level by the end of Grade 3, the chances of the child achieving academic success were severely compromised. In 1999, the Hamilton Wentworth Catholic District School Board established an Early unique perspective of the beginning reader and to implement the Ontario Ministry of Education requirement for the Early Reading Strategy.

As a member of the committee and with the cooperation of staff, we were able to pilot some initiatives at St. Helen School. These included the adoption of two hours daily for uninterrupted literacy, the use of leveled text for instruction, specific tools for assessment, the training of teachers to do Running Records, and refocusing of the intervention program. A Literacy links model of delivery of language instruction included time for Teacher Read Aloud, Shared Reading, Guided Reading, Independent or Self-Selected Reading, Writing and Word Study.

The Assessment tools used to inform instruction are the PM Benchmark Kit, the Yopp Singer Test of Phoneme Segmentation and an Observation Survey of Early Literacy Achievement [see bibliography notes for full details]. Our story is one of an ongoing journey to use assessment to maximize reading instruction and increase school success for each student. Literacy committee to look at the
Using Assessment to Inform Instruction of Guided Reading Groups... leveled text for classroom instruction

Primary teachers use the PM Benchmark Kit to take a Running Record to determine first of all each child's instructional level. Once all the children have been tested, the school Early Literacy team meets to determine the structure of the classroom instructional groups for the Guided Reading component of the literacy block. Each classroom teacher is responsible for teaching four Guided Reading instructional groups. Two Guided Reading lessons are taught every day, each lesson taking approximately thirty minutes, so each group receives a Guided Reading lesson on alternate days. Some children will remain with their own teacher for this half hour, others may go to another teacher, depending on their current instructional level. The Nelson Language Program which features leveled text selections is used as the core with supplementary readings borrowed from the Book Room. The school has a Book Room set up where books are organized from levels 1 to 30 according to Fountas and Pinnell (1999). Some books are multiple copies so the teacher can use them with a group, and some books are individual copies that can be placed in the child's Browsing Bin for Independent/Self-selected reading time or to borrow to take home in their Book Bag for additional practice.

Using Assessment to Inform Instruction that supports the beginning reader ... Browsing Bins

Every day, time is scheduled for Independent or Self-Selected Reading. The teacher arranges in Browsing Bins a selection of books to match each child's level. The 
number of bins varies according to the four guided reading levels the teacher is currently teaching, plus the bins for children receiving intervention and/or Guided Reading instruction with another teacher. During the Independent/ Self-selected reading time, the child has access to books at his or her specific level. This is extremely important as the beginning reader does not have the capability to follow the instruction often given by a teacher to "find a book to read at your level". Providing the child with a preselection of leveled text appropriate for the child's level prevents time being wasted and gives the child immediate tools to practice reading strategies. Also students are able to choose to take home books in their Take Home Book Bags for additional practice. The teacher knows that the child can read these books to a parent as the books are at the child's reading precise level. Frequently the Independent/Self-selected reading time is the time when the teacher takes Running Records. The practice of taking daily Running Records allows the teacher to determine which strategies to next teach that child or that group.

\section{Using Assessment to Inform In- struction of Specific Reading Strategies ... Daily Running re- cords}

Leveled texts are used for taking these Running Records instead of the PM Benchmark Kit which is reserved primarily for specific Assessment purposes. After taking the Running Record, the teacher makes a qualitative analysis of the child's reading behaviour, to determine which reading strategies the child is consistently using and which ones are not being used. The teacher looks at the child's use of Visual Information, Structure and Meaning and from the information decides what to focus on in the next Guided Reading Lesson. Each teacher aims to do at least one Running Record per child each month. The information can be used to determine whether the child needs more practice at that level or whether to move on to the next instructional level. A child who is in the Reading Recovery intervention program has a Running Record taken every day and a student in Early Success has one take a minimum of once a week.

\section{Using Assessment to Inform In-} struction for the struggling student ...Intervention Practices

Teachers refer to the School Resource Team any student who is not at level three in reading for that grade, according to Ontario Ministry of Education standards. The PM Benchmark Kit is used to take a Running Record to determine the child's instructional level. From here the school's Early Literacy Team determines what intervention program is appropriate, when the intervention will take place and who will be responsible for the intervention. [A child who has already been identified as a Special Needs student and who has an Individual Education Plan in place is not included in this procedure.] A child receiving intervention is also assigned to a classroom Guided Reading group.

Intervention for the struggling student is delivered through the use of four programs - Nelson Early Success, Nelson Soar to Success, Reading Recovery, and the "Intervention for Students Experiencing Delays in Specific Areas of Phonological Awareness" component from the Nelson Kindergarten Language Book. All students who receive intervention do so on a daily basis for between twenty and thirty minutes. Support to the school consists of half time Language Resource teacher, half time Reading Recovery and a full time Special Education Resource teacher, whose is also responsible for all Special needs students. Parents are invited to come and observe an intervention lesson so that they can assist their child at home.

The Nelson Early Success and Soar to Success Programs are used either with an individual child for twenty minutes daily or thirty minutes for a group of no more than two or three students. The Nelson Early Success Program targets students reading at levels one to fifteen, as measured using the PM Benchmark Kit and the Soar to Success Program targets levels fifteen to thirty. Our experience at St. Helen School has convinced us that if the child is struggling to learn how to read in a group of six or eight students in the classroom, that student is not able to maximize his or her learning in a group of this size, so the composition of the intervention group must be significantly different. The Early Success groups are organized according to the child's instructional level and the program is delivered by either the Language Resource teacher or the Special Education Resource Teacher. Each group has a span of no more than three instructional levels and, whenever possible, this is kept at two levels. The child moves from one instructional group to another based on measured progress. The aim is to provide intervention that is short term, targeted and measurable. Some children move very quickly and their achievement has to be accommodated, others need more time at a particular level. The Early Literacy Team meets every two weeks ro review and make the necessary adjustments to group structures. Once a child reaches the average for that grade level, the School Resource Team 
recommends demission from the intervention program.

This is significant departure from our old model of Language Intervention, where a child was put into an intervention group in September, with the Language Resource teacher, and that child stayed there until June.

The Reading Recovery Program specifically targets the lowest and oldest students in their grade one year. To determine who will receive the program, grade one students are tested in September using the Observation Survey of Early Literacy Achievement. A child whose score is low enters the program for a minimum of ten weeks. The Reading Recovery teacher sees four students one at a time for half an hour each every day. She uses daily Running Records to determine which reading strategy to teach the child. A student is successfully demitted when they reach the average for the class in instructional level in reading. This program is well researched and highly successful at preventing reading failure in grade one students.
Intervention for Students Experiencing Delays in Specific Areas of Phonological Awareness

This program targets those students in the primary grades who are experiencing delays in the acquisition of phonemic awareness . Research work by Dr. Betty Ann Levy of McMaster University in reading indicates that a student who has the double deficit of slow naming and poor phonemic awareness is at far greater risk for reading difficulties. At St Helen School we use the Yopp Singer Test of Phoneme Segmentation to determine which students are at risk in this area. A child who scores poorly is assigned to a small group of no more than four students to receive daily instruction for twenty minutes that focuses on delays in rhyming, segmentation, blending sound matching, sound isolation, and sound addition or substitution. This program is linked to the classroom literacy links of Working with Words and Word Study. A student is demitted when the test scores demonstrate significant improvement in this area.

This school story does not have an ending and probably never will, for as educators, we constantly search for ways to improve instruction to help even more students to reach their full potential. We can, however, report that our school EQAO grade three scores in Reading are showing improvement and, for us, giving the students the literacy skills they need for school success is like helping them to find the proverbial pot of gold at the end of the rainbow.

\section{Bibliography}

Clay, M.M. (1993). An Observation Survey of Early Literacy Achievement. Portsmouth, NH: Heinemann.

Fountas I. C. \& Pinnell G.S.(1999). Matching Books to Readers : A Leveled Book List for Guided Reading, K-3. Portsmouth, NH: Heinemann.

Nelley, E. \& Smith A. (2001). PM Benchmark Kit, Ontario: Nelson.

Stenby, S. (1999). Nelson Language Arts. Ontario: Nelson.

Tremaine, M. (2000). Kindergarten Teacher's Resource Book. Ontario: NeIson.

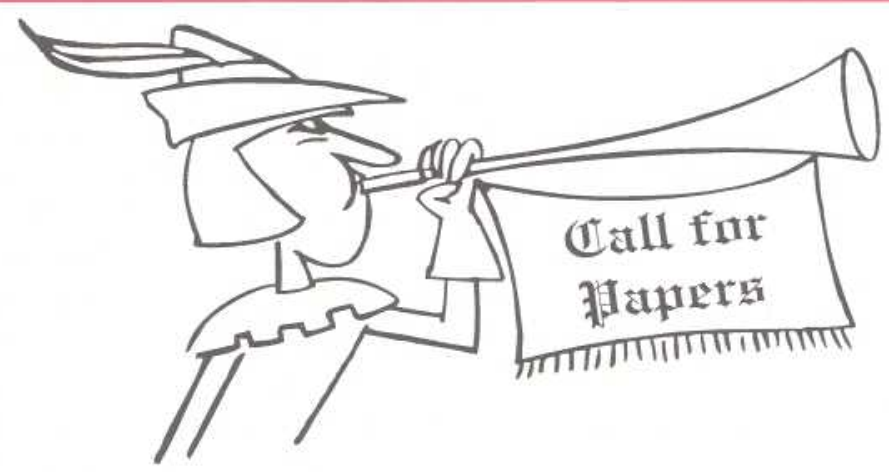

All manuscripts and other editorial communications should be sent to

Dr. Raymond T. Chodzinski, Editor
Teaching \& Learning
Faculty of Education, Brock University
1842 King Street East
Hamilton, Ontario L8K 1V7

Please include a hard copy with your electronic copy of the article. The electronic copy may be in Microsoft Word or in WordPerfect.
The Editor and the Editorial Board invite you to submit papers for the following thematic issues:

Vol. 1, No. 3 (Spring 2003)

"Conflict resolution and School Bullying" edited by Raymond T. Chodzinski Deadline for submission of papers: June 1, 2003

Vol. 1, No. 4 (Summer 2003)

"Leadership in Education" Guest Editor, Michael Manley-Casimir Deadline for submission of papers: July 1, 2003

Vol. 2, No. 1 (Fall 2003)

"Technology in Education"

Guest Editor, Leo Elshop

Deadline for submission of papers:

September 1, 2003 